\title{
Teacher Involvement Prevents Increases in Children's Depressive Symptoms: Bidirectional Associations in Elementary School
}

\author{
Jantine L. Spilt \& Geertje Leflot \& Hilde Colpin \\ KU Leuven, Belgium
}

April 2018

https://rdcu.be/OjJT

Correspondence to: Jantine.spilt@kuleuven.be 


\section{Teacher Involvement Prevents Increases in Children's Depressive Symptoms: Bidirectional Associations in Elementary School}

There is accumulating evidence that social relationships can buffer the development of depression in childhood and adolescence. However, few studies have focused on teacher-child relationships in the elementary school years. In addition, research that has examined bidirectional relations between teacher involvement and depressive symptoms is virtually absent in this age period. The participants in this study were 570 children and 30 teachers from 15 elementary schools. Data on children's depressive symptoms (peer- and teacherreports) and teacher involvement (teacher-reports) were collected in the fall and spring of Grade 2 and Grade 3 (four waves). As expected, negative cross-time effects of teacher involvement on depressive symptoms were found within grade 2 and 3. In addition, a negative cross-time effect of depressive symptoms on teacher involvement was found in grade 3 only. The results thus indicate the protective role of teacher involvement in the development of depressive symptoms but also suggest that teachers may become less involved over time when they perceive a child as more depressed.

Keywords: teacher-child relationships, teacher involvement, child depression 


\section{Teacher Involvement Prevents Increases in Children's Depressive Symptoms: Bidirectional Associations in Elementary School}

Social experiences have a powerful impact on children's development. In a recent meta-analysis, supportive relationships at home and at school have been shown to be robust predictors of lower levels of depression in childhood and adolescence (Rueger, Malecki, Pyun, Aycock, \& Coyle, 2016). The present study contributes to research on social relationships in three ways. First, in comparison to relationships with parents and peers, relationships with teachers have received little attention. Second, research on depression has predominantly focused on adolescents, whereas research in preadolescent children is scarce (Rueger et al., 2016). Especially in the elementary school years where children typically have one teacher, positive teacher-child relationships may be a protective factor for children showing first symptoms of depression. Third, few studies have examined the direction of effects between social relationships and depression (Rueger et al., 2016). This is unfortunate because depressive symptoms can cause impaired social functioning. Consequently, poor relationship quality may be an outcome of depression rather than an antecedent of depression. In the present four-wave study, we examined the effects of teacher involvement on depressive symptoms of children within and across two school years in an autoregressive cross-lagged model to disentangle the direction of effects.

\section{Depressive Symptoms in the Elementary School Years}

Although the prevalence of depressive disorders among elementary school children is relatively low (Pulkkinen, Kaprio, \& Rose, 1999), early depressive symptoms do not seem to be innocent or transient phenomena. Research shows that depressive symptoms gradually increase across the elementary school years (Keenan, Feng, Hipwell, \& Klostermann, 2009). Moreover, Ialongo et al. (1993) found that depressive symptoms in first grade predict depressive symptoms in fifth grade. Likewise, Keenan et al. (2009, p.1173) reported that "for each change in the number of depressive symptoms there is approximately a 50-80\% increase in the risk of meeting criteria for a depressive disorder in early adolescence". Researchers have called for early intervention to prevent children with mild depressive symptoms from developing a depressive disorder in adolescence or adulthood (Gladstone \& Beardslee, 2009; Keenan et al., 2009). Consequently, there is increased attention for schools as contexts for the prevention of childhood depression (Merry et al., 2012).

Most of the current school-based interventions are child-focused and rely on cognitive-behavioral approaches (Spence \& Shortt, 2007). However, programs focused on individual skills and characteristics of children may not be sufficiently effective when social environmental factors are not targeted (Spence \& Shortt, 2007). It is therefore key to identify environmental factors that have an impact on the development of depression. Although research has demonstrated that teachers may affect children's socio-emotional development, studies have mainly focused on school adjustment (e.g., Hughes, 2012) or on externalizing behaviors (e.g., O’Connor, Dearing, \& Collins, 2011); child depression has been understudied. From a prevention perspective this is unfortunate, because insight in normative social processes is critical to identify protective mechanisms through which depression can be prevented in children's natural environments.

\section{Positive Teacher-Child Relationships and Child Depression}

The importance of positive relationships with teachers is emphasized in different theoretical frameworks. The main effect model or general benefits model of social support

This is a post-peer-review, pre-copyedit version of an article published in Journal of Abnormal Child Psychology. The final authenticated version is available online at: https://doi.org/10.1007/s10802- 
(Cohen \& Wills, 1985; Rueger et al. 2016) posits that supportive relationships contribute to children's emotional and psychological wellbeing by enhancing positive affect, feelings of belonging, self-worth, acceptance, and efficacy beliefs. The importance of positive relationships and interpersonal attachments is also recognized in the self-determination theory (Connell \& Wellborn, 1991; Deci \& Ryan, 2000) and the need to belong hypothesis (Baumeister \& Leary, 1995). In these frameworks, the need to belong is considered a basic psychological need. Fulfillment of this need through positive relationships with others promotes well-being, whereas frustration of this need leads to mental health problems (e.g., Ibarra-Rovillard \& Kuiper, 2011). Guided by attachment theory, it is posited that sensitive teachers provide children a safe haven and a secure base for exploration (Howes, Phillipsen, \& Peisner-Feinberg, 2000; Verschueren \& Koomen, 2012). Supportive teachers help children to cope with social-emotional and academic challenges in the school context in such a way that they feel more emotionally secure, experience less stress (Little \& Kobak, 2003), and are less likely to develop internalizing problems (O'Connor et al., 2011).

According to the bioecological models of development, child development is a complex transactional process between characteristics of the child and characteristics of the environment, that unfolds over time. Children are not passive but shape their environments and thus may elicit different amounts of support from teachers (Coplan \& Prakash, 2003). Specifically, depressed children may be less successful in eliciting positive interactions with teachers, which in turn may reinforce depressive symptoms. This hypothesis is in accordance with the stress-generation theory of depression, which postulates that depressed people exhibit cognitive and interpersonal vulnerabilities that increase interpersonal stress, creating a downward spiral between depression and stress (Liu \& Alloy, 2010).

Positive teacher-child interactions can thus be a predictor or an outcome of depression or both; the latter suggesting bidirectional associations. To disentangle the direction of effects, autoregressive cross-lagged models have been advocated as optimal, yet conservative tests (Jöreskog, 1970; Masten \& Cicchetti, 2010). In these models, cross-time or bidirectional associations between constructs are tested while controlling for the stability of the constructs over time as well as concurrent correlations between the constructs. Only a few studies have analyzed cross-lagged models of bidirectional associations between teacher-child relationships and child depression. To our knowledge, two studies have investigated these links over the course of multiple school years. Ly and Zhou (2016) conducted a two-wave study in an elementary school sample of Chinese-American immigrant children. They found no prospective cross-time effects between teacher-reported internalizing problems and positive (close) teacher-child relationships. In a substantially large sample of Australian adolescents, however, Pössel et al. (2013) found that increases in teacher emotional support predicted decreases in depression from grade 8 to 12 (but not vice versa).

Moreover, a handful of studies have examined bidirectional associations within a single school year. These studies have focused predominantly on young children. Roorda et al. (2014) examined teacher-child relationship quality and child internalizing problems in preschool boys with serious externalizing problems. Surprisingly, they found that internalizing problems predicted closer teacher-child relationships. But this effect may be specific for young boys with severe conduct problems. Zhang and Sun (2011) found no crosswave associations between positive teacher-child relationships (closeness) and internalizing problems in preschool in a relatively small two-wave study. Likewise, Meija and Hoglund (2016) found no cross-wave associations between positive teacher-child relationships (closeness) and internalizing problems across a single school term in a low-income and ethnically-diverse sample that included children from kindergarten to grade 3.

This is a post-peer-review, pre-copyedit version of an article published in Journal of Abnormal Child Psychology. The final authenticated version is available online at: https://doi.org/10.1007/s10802- 
In sum, the few studies that have tried to disentangle the direction of effects between teacher-child relationships and depression (or internalizing problems) have yielded mixed evidence. Although it is too early to draw conclusions, it could be that supportive teacherchild relationships are mainly important for older students (i.e., adolescents, see Pössel et al. 2013). To our knowledge, no study has focused specifically on bidirectional effects between depression and teacher-child relationships in a non-risk elementary school sample.

\section{The Present Study}

In the present four-wave study, we measured teacher involvement and depressive symptoms in the fall and spring of grade 2 and grade 3 to examine within and across year effects between teacher involvement and child depressive symptoms in a community-based sample. Teacher involvement was chosen as an indicator of a positive teacher-child relationship referring to a teacher's positive feelings for a student and provision of support. We expected that higher levels of involvement would be associated with less depressive symptoms over time. In line with bioecological models of development, we also investigated whether changes in child depressive symptoms would be predictive of changes in teacher involvement (i.e., bidirectional associations). Consistent with a recent meta-analysis on supportive relationships and depression (Rueger et al., 2016), we expected no gender differences in the effects of teacher involvement on depressive symptoms.

\section{Method}

\section{Participants}

The sample included 570 children ( $49.5 \%$ boys) and 30 teachers from 15 regular primary schools serving grades 1 to 6 . The schools were located in the Flemish community of Belgium. Written informed consent was obtained from parents (participation rate 97\%). At the start of the study (fall of Grade 2), children were on average 7 years and 5 months old ( $S D$ $=4.6$ months). The vast majority of children (>95\%) had the Belgian nationality, 4 children had the nationality from another European country, and 4 children from an African country. For the remaining children, we did not have information about their nationality. Most of their parents were highly educated $(63 \%$ of the mothers and $57 \%$ of the fathers had completed college or university, relative to 51 and $36 \%$ of the Flemish population; Belgian Federal Government 2009).

Children usually had one classroom teacher (90-93\% across grades). Classroom peer composition did not change between second and third grade; only the teachers changed, which is common in the Flemish educational system. Over the two-year study period, 41 children dropped out of the study because of grade retention or because of changing schools. Attrited children were rated significantly lower on teacher involvement (Cohen's $d=-0.73$ ) and higher on teacher-rated (but not peer-rated) depressive symptoms (Cohen's $d=.54$ ) than the non-attrited children at the start of the study.

\section{Procedure}

The study was part of a larger randomized-controlled intervention study on behavioral classroom adjustment and school influences (Leflot, van Lier, Onghena, \& Colpin, 2010) that was approved by the Ethical Committee of the KU Leuven. Given this specific interest, child's behavioral displays of depression at school were rated by peers and teachers. Teachers and peers have been found to be reliable reporters of depressive symptoms and anxiety in children (Pulkkinen et al., 1999). Half of classrooms were randomly assigned to a preventive intervention, the Dutch version of the Good Behavior Game (Dolan, Jaylan, Werthamer, \& Kellam, 1989; Van der Sar \& Goudswaard, 2001), which is a teacher-delivered, group 
contingency management procedure for reducing disruptive and promoting on-task behavior. Teacher completed questionnaires (73 items per child) and children were interviewed in fall and spring of second grade (Wave $1 \& 2$ ), and again in fall and spring of third grade (Wave 3 $\& 4)$. Teachers were trained and implemented the GBG during two consecutive grades from mid-October to mid-May, leaving sufficient time for data collection before and after. Research showed that the GBG reduced children disruptive behavior through a reduction in teachers' use of behavior corrections (Leflot et al., 2010) and a decrease in peer rejection (Leflot, van Lier, Onghena, \& Colpin, 2013).

\section{Measures}

Teacher-reported depressive symptoms. Teacher perceptions of child depressive behavior were assessed using the Depression subscale of the written questionnaire Problem Behavior at School Interview-revised (PBSI-r; Erasmus Medical Center, 2000). Teachers rated 7 items (e.g., "Cries or is sad at school"; $\alpha=.77-.83)$ on a 5-point Likert scale ( $0=$ never applicable; $4=$ often applicable). The Depression and Anxiety scales of the PBSI correlated significantly with the Internalizing scale of the Teacher Report Form in a sample of firstgrade children $(r=.55, p<.01$, Witvliet, Van Lier, Cuijpers, \& Koot, 2009), and have demonstrated sensitivity to change induced by a preventive intervention in Grade 1 (Spilt, Koot, \& van Lier, 2013).

Peer-reported depressive symptoms. To measure peer perceptions of children's depressive behaviors, children were asked to nominate all classmates who met the behavioral description "Is often sad" following widely-used procedures for peer nomination assessments (Cillessen \& Bukowski, 2000). They were given a set of photographs of all children in their class. For each child, the number of nominations was divided by the number of participating children minus 1 (children were not allowed to nominate themselves). Research has reported standardized factor loadings of .58 to .70 of peer nominations in a multi-informant model of depression in third and sixth grade, providing support for convergent validity (Cole, Martin, Powers, \& Truglio, 1996).

Teacher Involvement. The Involvement subscale of the Teacher as Social Context (TASC) measures teacher-reported affection, attunement, dedication of resources, and dependability (Wellborn, Connell, Skinner, \& Pierson, 1992). The scale includes 14 items ("I enjoy spending time with this student"; "When this student does not do as well as s/he can, I can make time to help him/her find ways to do better"; $\alpha=.84-.88$ ) that were assessed on a 4point-scale $(0=$ not at all true; $3=$ very true $)$. In support of the scale's predictive validity, teacher involvement in fall has been found to significantly predict child perceptions of teacher support and child engagement in spring in elementary school children (Skinner \& Belmont, 1993).

\section{Analysis Plan}

The autoregressive cross-lagged models were analyzed in Mplus (Muthén \& Muthén, 1998-2012). The MLR estimator was used to evaluate model fit accounting for the multilevel variance (children nested in teachers). The alpha level was set at .05.

Model fitting. Given the number of variables in the model, many models may fit the data well. Therefore, it is a common strategy in testing autoregressive cross-lagged models to compare the model fit of increasingly complex models in order to identify the most parsimonious model. We tested a series of three nested models separately for teacher-rated and peer-rated child depressive symptoms: an autoregressive model (baseline model), a child effects model, and a child + teacher effects model (full transactional model). First, the autoregressive model included only autoregressive paths (i.e., stability within constructs) and cross-sectional correlations (model 1: baseline model). For each path, we used the Wald test

This is a post-peer-review, pre-copyedit version of an article published in Journal of Abnormal Child Psychology. The final authenticated version is available online at: $\underline{\text { https://doi.org/10.1007/s10802- }}$ 
to examine whether there were differences between grades (i.e., whether paths from Wave 1 to Wave 2 and paths from Wave 3 to Wave 4 were similar). We also tested whether the crosssectional associations between support and depressive symptoms were similar in the fall and spring. When the differences were non-significant, the paths were constrained to be equal. When the differences were significant or near significant, the paths were allowed to differ. Finally, we also included the effects of gender and intervention condition. Only significant effects were retained in the baseline model. In the second model, we added cross-time paths from child depressive symptoms to teacher involvement one wave later to examine child effects (model 2: baseline model + child effects). We also tested whether the cross-time paths differed across grades. Cross-time paths were constrained to be equal when there were no significant differences. Finally, non-significant paths were removed in the second model. In the third step, we added cross-time paths from teacher involvement to child depressive symptoms (model 3 = baseline + child effects + teacher effects) and tested differences in cross-time paths across grades. As a final step, we examined gender differences in the crosstime paths in the selected model. We re-estimated the model (without including gender as a covariate) in a multi-group model for boys and girls. The Wald test was used to test gender differences in cross-time paths between support and depressive symptoms by constraining paths to be equal. We also ran multi-group models across conditions (intervention vs. control) and found non-significant condition differences in cross-lagged paths using the Wald test.

Missing data. The covariance coverage matrix provides information on the extent of missing data estimation for the remaining sample. The covariance coverage ranged between 0.928 to 1.000 across all data points in the teacher-rated depressive symptoms model and between 0.925 to 1.000 in the peer-rated depressive symptoms model, indicating very low rates of missing data. Incomplete data on the dependent variables was handled using full information maximum likelihood (FIML) estimation. Cases with missing data on the independent variables were excluded (two cases in the teacher-rated depressive symptoms model).

\section{Results}

The descriptive statistics are presented in Table 1. The correlations between teacherrated and peer-rated depressive symptoms were significant but small. The correlations between teacher-rated depressive symptoms within grades (rated by the same teacher) were moderately large ( $r=.58$-.63) but the correlation between grades (rated by different teachers) was small ( $r=.21$ from Wave 2 to 3 ). The correlations between peer-rated depressive symptoms were relatively high within and across grades $(r=.60-.70)$. Teacher involvement correlated negatively with teacher-rated depressive symptoms but not with peer-rated depressive symptoms. Furthermore, teacher involvement was quite stable within grades $(r=$ .64-.66) but not between grades ( $r=.09$ from Wave 2 to 3 ).

\section{Teacher Involvement and Teacher-Rated Child Depressive symptoms}

First, we examined a baseline model including autoregressive paths (i.e., stability within constructs) and cross-sectional correlations. Gender was included as a time-invariant covariate. Intervention condition was not significant and therefore removed from the model. We used the Wald test to examine differences across school years. There were no differences in fall-to-spring stability in Support between Grade 2 and 3, no differences in fall-to-spring stability in Depressive symptoms, and no differences in cross-sectional associations between Depressive symptoms and Support in the fall and in the spring ( $p s>.05)$. These paths were therefore constrained to be equal across grades (model 1: baseline). 
Second, cross-time paths from Depressive symptoms to Support were added to model 1. The difference in cross-time paths from Wave 1 Depressive symptoms to Wave 2 Support and from Wave 3 Depressive symptoms to Wave 4 Support was near significant $(p=.06)$ and therefore freely estimated across grades. Only the path from Wave 3 Depressive symptoms to Wave 4 Support was significant, indicating a negative effect of Depressive symptoms on Support in Grade 3 only. The non-significant paths were removed from the model (model 2: baseline + child effects $)$. The difference between model 1 and 2 was significant $\left(\Delta \mathrm{SB} \chi^{2}(1)=\right.$ $52.769, p<.05)$.

Third, cross-time paths from Support to Depressive symptoms were added. The crosstime paths from Wave 1 to Wave 2 and from Wave 3 to Wave 4 were not significantly different, suggesting no differences between grades, and were therefore constrained to be equal $(p>.05)$. The cross-time path from Wave 2 Support to Wave 3 Depressive symptoms was not significant and therefore removed from the model (model $3=$ baseline + child effects + teacher effects). The difference between model 2 and 3 was significant $\left(\Delta \mathrm{SB} \chi^{2}(1)=4.743\right.$, $p<.05)$. Therefore, model 3 was selected as the final model. The fit of this model was good: $\chi^{2}(33)=24.3$; RMSEA=.00; SRMR=.06; CFI=1.00 (Hu \& Bentler, 1999). Teacher involvement predicted less depressive symptoms in both Grade 2 and 3, whereas depressive symptoms predicted less support only in Grade 3 (Table 2 and Figure 1).

Furthermore, we examined gender differences in a multi-group model with all parameters freely estimated across gender. Only the cross-time path from Wave 1 Depressive symptoms to Wave 2 Support was significantly different $(p<.05)$. Depressive symptoms predicted less Support for boys $(B=-.05, p=.48)$, whereas more support for girls $(B=.05, p=$ .42 ). However, in both subgroups, this effect was not significantly different from zero and could therefore be considered trivial.

\section{Teacher Involvement and Peer-Rated Child Depressive symptoms}

As for peer-rated depressive symptoms, we first examined the auto-regressive model. Again, gender was included as a time-invariant covariate. Intervention condition was not significant and therefore removed from the model. There were no grade differences in fall-tospring stability in Support, no grade differences in fall-to-spring stability in Depressive symptoms, and no grade differences in cross-sectional associations between Depressive symptoms and Support in the fall and in the spring ( $p s>.05)$. These paths were constrained to be equal across grades (model 1: baseline).

Second, cross-time paths from Depressive symptoms to Support were added to model 1 (model 2 baseline + child effects model). The grade differences in paths from Wave 1 Depressive symptoms to Wave 2 Support and from Wave 3 Depressive symptoms to Wave 4 Support were non-significant $(p>.05)$ and therefore constrained to be equal across grades. However, these paths were found non-significant indicating no child effects. Consequently, the paths were removed so that the model was similar to the baseline model.

Third, cross-time paths from Support to Depressive symptoms were added (model 3: baseline + teacher effects model). The paths from Wave 1 to Wave 2 and from Wave 3 to Wave 4 were not significantly different across grades and were therefore constrained to be equal $(p>.05)$. All cross-time paths from Support to Depressive symptoms were significant and the model showed a significant improvement $\left(\Delta \mathrm{SB} \chi^{2}(2)=21.928, p<.01\right)$ to the baseline model resulting in the final model $\left(\chi^{2}(26)=79.6 ; \mathrm{RMSEA}=.06 ; \mathrm{SRMR}=.08 ; \mathrm{CFI}=.94\right)$. Support predicted less peer-rated Depressive symptoms from fall-to-spring. However, from spring to fall, Support predicted more peer-rated Depressive symptoms (Table 2 and Figure 2). 
Furthermore, gender differences in each cross-lagged path were tested in a multi-group model. A significant difference $(p<.05)$ was found from Wave 3 Support to Wave 4 Depressive symptoms, suggesting a significant negative effect for girls only (Table 2).

\section{Discussion}

The rate of depressive symptoms in the elementary school years is generally low. However, depressive symptoms are quite stable and research has shown that early depressive symptoms seriously increase the risk of depressive episodes in adolescence and adulthood (Ialongo et al, 1993; Keenan et al., 2009). Consequently, efforts have been made to deliver preventive interventions in school settings for children at-risk (Gladstone \& Beardslee, 2009; Keenan et al., 2009). However, these preventive interventions may be more effective when social environmental factors in the school are included as targets (Spence \& Shortt, 2007). One such factor may be the involvement of a child's teacher.

In line with theoretical models underscoring the beneficial effects of positive relationships and attachment (e.g., general benefits model, self-determination theory, need to belong hypothesis, and attachment theory), the present four-wave study suggests that teacher involvement plays a significant role in the development of depressive symptomatology in the elementary school years. Teacher involvement consistently predicted fall-to-spring changes in child depressive symptoms such that high support predicted less depressive symptoms. These findings were found while controlling for concurrent associations and controlling for opposite effects, and were robust across informants and grades. The results may suggest causality but randomized-controlled trials are needed to prove this.

Although we consistently found that teacher involvement predicted less depressive symptoms, one opposite effect was found as well. Unexpectedly, higher teacher involvement in the spring of grade 2 predicted more depressive behavior in the fall of grade 3 as observed by peers. Perhaps, children who had a supportive teacher in grade 2 may have had more difficulties adjusting to their new teacher in grade 3 , resulting in more insecure and depressive behavior at the beginning of grade 3. It is also possible that an unmeasured 'third' variable, like a child's difficulties at home, accounts for this association. Perhaps vulnerable children with a stronger need for supportive teacher-child relationships respond more negatively to the general decline in teacher involvement that has been observed over the course of elementary school (Jerome, Hamre, \& Pianta, 2009) and that was also seen in our data. However, it should be noted that this increase in depressive symptoms was not observed by the teachers of grade 3 . The finding needs replication in future research.

In addition, there was some evidence that relationships between teachers and depressed children deteriorated over time. In grade 3, we found that child depressive symptoms in fall predicted lower levels of teacher involvement in spring. Importantly, this was found only for teacher-reported child depressive symptoms and not for peer-reported child depressive symptoms, suggesting that teachers who perceive children as more depressed tend to become less involved with these children over time. It is possible that interactions with depressed children are less enjoyable for teachers or that it is more difficult to stay in tune with these children. Alternatively, the withdrawal of the teacher may be a consequence of the social malfunctioning of the child. According to the stress generation hypothesis, depressed individuals elicit more interpersonal hassles due to cognitive and interpersonal vulnerabilities (e.g., negative attribution styles, rumination, maladaptive coping), which harms the quality of interpersonal relationships (Liu \& Alloy, 2010). It is not clear why this was found only in grade 3 and not in grade 2. It is possible that teachers become less tolerant of children's emotional dysregulation when children grow older.

This is a post-peer-review, pre-copyedit version of an article published in Journal of Abnormal Child Psychology. The final authenticated version is available online at: $\underline{\mathrm{https}} / / /$ doi.org/10.1007/s10802- 
Overall, the findings were consistent across gender (cf. Rueger et al., 2016). We found a small difference only in the peer-rated model and only in grade 3, that is a negative effect of support on depressive symptoms for girls and not boys. This is consistent with the gender socialization theory, which posits that girls are more strongly influenced by supportive relationships because they are more socially oriented (Maccoby, 1998).

In conclusion, this prospective four-wave study revealed cross-time effects of teacher involvement on child depressive symptoms within 2 nd and 3 rd grade. This was not found in previous autoregressive cross-lagged studies modelling within-year changes in preschool samples (Mejia \& Hoglund, 2016; Roorda et al., 2014; Zhang \& Sun, 2011). The competencybased model of depression can provide a possible explanation (Cole, 1990). According to this model, children internalize relational experiences in adaptive or maladaptive self-cognitions that protect or predispose children to develop depression. The construction of competencybased self-cognitions is a developmental task of middle childhood. Therefore, support may have a stronger impact on depression in elementary school (and secondary school, see Pössel et al., 2013) than in preschool.

\section{Limitations and Future Research}

The positive effects of teacher involvement were consistent across informants and grades, thereby strengthening the final conclusion that teacher involvement can be considered a protective factor in the development of depression. However, children's own reports of depressive symptomatology were not included. This may have resulted in an underestimation of depressive symptoms because peers and teachers may not be fully aware of a child's internal state. Neither did we have data on children's perceptions of teacher involvement, whereas research shows that teachers' and children's reports of relationship quality and support are only modestly related (e.g., Hughes, 2011). Third, although auto-regressive crosslagged models have been advocated as optimal, yet conservative tests (Masten \& Cicchetti, 2010), we cannot rule out the possibility that the associations between teacher involvement and child depressive symptoms were driven by an unknown third variable. Fourth, the effects of teacher involvement on depressive symptoms appeared substantial given the stability in depressive symptoms and the moderately-large bivariate correlations (which were controlled for in the model, Adachi \& Willoughby, 2015). However, the effects of teacher involvement on peer-rated depressive symptoms seemed less strong. Finally, over $95 \%$ of the children had the Belgian nationality but we had no information about ethnicity and cultural background . Positive relationships may be more important for the psychological adjustment of ethnicminority students (Roorda, Koomen, Spilt, \& Oort, 2011) but there is also evidence that ethnic mismatch is associated with more conflictual teacher-child relationships (Spilt \& Hughes, 2015).

The current study highlights the importance of positive teacher-child relationships, pointing to the need for teachers to be involved with individual children. Future research may examine additional research questions. For example, it would be interesting to know what aspects of involvement, that is affection, understanding, availability or support account for the protective effects of involvement on the development of depressive symptoms. Furthermore, future research could examine how teachers perceive and respond to the dysfunctional and stress-generating behaviors of depressed children or to what extent teachers can play an active role in attribution retraining to change children's helplessness attributions (i.e., attributing failure to uncontrollable and internal causes) in the face of everyday school challenges (Nolen-Hoeksema, Girgus, \& Seligman, 1992). 


\section{Practical Implications}

The results demonstrated that teacher involvement is not merely a correlate or consequence of child depressive symptomatology. Instead, teacher involvement seems a mechanism through which depressive symptoms can be prevented in the elementary school years, thereby reducing the risk of a depressive disorder in adolescence. Intervention research indicates that teacher training is a promising component of interventions targeting internalizing problems (Herman, Borden, Reinke, \& Webster-Stratton, 2011). Specifically, preventive interventions that include a module for building positive teacher-child relationships could strengthen schools in providing children a secure context for a healthy emotional development (Hughes, 2012). This may be especially important for children who are less successful in eliciting support from teachers because of social impairment or withdrawal or other interpersonal vulnerabilities.

\section{References}

Adachi, P., \& Willoughby, T. (2015). Interpreting effect sizes when controlling for stability effects in longitudinal autoregressive models: Implications for psychological science. European Journal of Developmental Psychology, 12(1), 116-128. doi:10.1080/17405629.2014.963549

Baumeister, R. F., \& Leary, M. R. (1995). The need to belong: Desire for interpersonal attachments as a fundamental human motivation. Psychological Bulletin, 117, 497-529.

Belgium Federal Government (2009). Educational level of the Belgium population. Retrieved from http://statbel.fgov.be

Cillessen, A. H. N., \& Bukowski, W. M. (2000). Recent advances in the measurement of acceptance and rejection in the peer system. New York: Jossey-Bass.

Cohen, S., \& Wills, T. (1985). Stress, social support, and the buffering hypothesis. Psychological Bulletin, 98(2), 310-357. doi:10.1037/0033-2909.98.2.310

Cole, D. A. (1990). Relation of social and academic competence to depressive symptoms in childhood. Journal of Abnormal Psychology, 99(4), 422-429. doi:10.1037/0021-843x.99.4.422

Cole, D. A., Martin, J. M., Powers, B., \& Truglio, R. (1996). Modeling causal relations between academic and social competence and depression: A multitrait-multimethod longitudinal study of children. Journal of Abnormal Psychology, 105(2), 258-270. http://dx.doi.org/10.1037/0021-843X.105.2.258

Connell, J. P., \& Wellborn, J. G. (1991). Competence, autonomy, and relatedness: A motivational analysis of self-system processes. In M. R. Gunnar \& L. A. Sroufe (Eds.), Self processes and development (Vol. 23, pp. 43-77). Hillsdale, NJ: Erlbaum.

Coplan, R. J., \& Prakash, K. (2003). Spending time with teacher: Characteristics of preschoolers who frequently elicit versus initiate interactions with teachers. Early Childhood Research Quarterly, 18(1), 143-158.

Deci, E. L., \& Ryan, R. M. (2000). The "What" and "Why" of goal pursuits: Human needs and the selfdetermination of behavior. Psychological Inquiry, 11, 227-268.

Dolan, L. J., Jaylan, T., Werthamer, L., \& Kellam, S. G. (1989). The Good Behavior Game manual. Baltimomore, MD: The Johns Hopkins Prevention Research Center.

Erasmus Medical Center. (2000). Problem Behavior at School Interview. Rotterdam: Erasmus University.

Gladstone, T. R., \& Beardslee, W. R. (2009). The Prevention of Depression in Children and Adolescents: A Review. The Canadian Journal of Psychiatry, 54(4), 212-221. doi:10.1177/070674370905400402

Herman, K. C., Borden, L. A., Reinke, W. M., \& Webster-Stratton, C. (2011). The Impact of the Incredible Years Parent, Child, and Teacher Training Programs on Children's Co-Occurring Internalizing Symptoms. School Psychology Quarterly, 26(3), 189-201. doi:10.1037/a0025228

Howes, C., Phillipsen, L. C., \& Peisner-Feinberg, E. (2000). The consistency of perceived teacher-child relationships between preschool and kindergarten. Journal of School Psychology, 38, 113-132.

Hu, L. t., \& Bentler, P. M. (1999). Cutoff criteria for fit indexes in covariance structure analysis: Conventional criteria versus new alternatives. Structural Equation Modeling: A Multidisciplinary Journal, 6(1), 1-55. doi:10.1080/10705519909540118

Hughes, J. N. (2011). Longitudinal effects of teacher and student perceptions of teacher-student relationship qualities on academic adjustment. The Elementary School Journal, 112(1), 38-60. doi:10.1086/660686

Hughes, J. N. (2012). Teacher-student relationships and school adjustment: progress and remaining challenges. Attachment \& Human Development, 14(3), 319-327. doi:10.1080/14616734.2012.672288

This is a post-peer-review, pre-copyedit version of an article published in Journal of Abnormal Child Psychology. The final authenticated version is available online at: $\underline{\text { https://doi.org/10.1007/s10802- }}$ 
Ialongo, N., Edelsohn, G., Werthamer-Larsson, L., Crockett, L., \& Kellam, S. (1993). Are self-reported depressive symptoms in first-grade children developmentally transient phenomena? A further look. Development and Psychopathology, 5(03), 433-457.

Ibarra-Rovillard, M. S., \& Kuiper, N. A. (2011). Social support and social negativity findings in depression: Perceived responsiveness to basic psychological needs. Clinical Psychology Review, 31(3), 342-352. doi:http://dx.doi.org/10.1016/j.cpr.2011.01.005

Jerome, E. M., Hamre, B. K., \& Pianta, R. C. (2009). Teacher-child relationships from kindergarten to sixth grade: Early childhood predictors of teacher-perceived conflict and closeness. Social Development, 18, 915-945. doi:10.1111/j.1467-9507.2008.00508.x

Jöreskog, K. G. (1970). A general method for analysis of covariance structures. Biometrika, 57, $239-251$. doi:10.1093/biomet/57.2.239

Keenan, K., Feng, X., Hipwell, A., \& Klostermann, S. (2009). Depression begets depression: Comparing the predictive utility of depression and anxiety symptoms to later depression. Journal of Child Psychology and Psychiatry, 50(9), 1167-1175. doi:10.1111/j.1469-7610.2009.02080.x

Leflot, G., van Lier, P., Onghena, P., \& Colpin, H. (2010). The role of teacher behavior management in the development of disruptive behaviors: An intervention study with the Good Behavior Game. Journal of Abnormal Child Psychology, 38, 869-882. doi:10.1007/s10802-010-9411-4

Leflot G., van Lier P., Onghena P., Colpin H. (2013). The role of children's on-task behavior in the prevention of aggressive behavior development and peer rejection: A randomized controlled study of the Good Behavior Game in Belgian elementary classrooms. Journal of School Psychology, 51, 187-199.

Little, M., \& Kobak, R. (2003). Emotional Security With Teachers and Children's Stress Reactivity: A Comparison of Special-Education and Regular-Education Classrooms. Journal of Clinical Child \& Adolescent Psychology, 32(1), 127-138. doi:10.1207/S15374424JCCP3201_12

Liu, R. T., \& Alloy, L. B. (2010). Stress generation in depression: A systematic review of the empirical literature and recommendations for future study. Clinical Psychology Review, 30(5), 582-593. doi:10.1016/j.cpr.2010.04.010

Ly, J., \& Zhou, Q. (2016). Bidirectional Associations Between Teacher-Child Relationship Quality and Chinese American Immigrant Children's Behavior Problems. Journal of Clinical Child \& Adolescent Psychology, 1-13.

Maccoby, E. E. (1998). The two sexes: Growing up apart, coming together. Cambridge, MA: Belknap Press/Harvard University Press.

Masten, A. S., \& Cicchetti, D. (2010). Developmental cascades. Development and Psychopathology, 22, 491495. doi:doi:10.1017/S0954579410000222

Mejia, T. M., \& Hoglund, W. L. G. (2016). Do children's adjustment problems contribute to teacher-child relationship quality? Support for a child-driven model. Early Childhood Research Quarterly, 34, 13-26. doi:http://dx.doi.org/10.1016/j.ecresq.2015.08.003

Merry, S. N., Hetrick, S. E., Cox, G. R., Brudevold-Iversen, T., Bir, J. J., \& McDowell, H. (2012). Cochrane Review: Psychological and educational interventions for preventing depression in children and adolescents. Evidence-Based Child Health: A Cochrane Review Journal, 7(5), 1409-1685. doi:10.1002/ebch.1867

Muthén, L.K. and Muthén, B.O. (1998-2012). Mplus User's Guide. Seventh Edition. Los Angeles, CA: Muthén \& Muthén

Nolen-Hoeksema, S., Girgus, J. S., \& Seligman, M. E. (1992). Predictors and consequences of childhood depressive symptoms: A 5-year longitudinal study. Journal of Abnormal Psychology, 101(3), 405-422. doi:10.1037/0021-843x.101.3.405

O’Connor, E. E., Dearing, E., \& Collins, B. A. (2011). Teacher-child relationship and behavior problem trajectories in elementary school. American Educational Research Journal, 48, 120-162. doi:10.3102/0002831210365008

Pössel, P., Rudasill, K. M., Sawyer, M. G., Spence, S. H., \& Bjerg, A. C. (2013). Associations between teacher emotional support and depressive symptoms in Australian adolescents: A 5-year longitudinal study. Developmental Psychology, 49(11), 2135.

Pulkkinen, L., Kaprio, J., \& Rose, R. J. (1999). Peers, teachers and parents as assessors of the behavioural and emotional problems of twins and their adjustment: the Multidimensional Peer Nomination Inventory. Twin Research, 2(4), 274-285. doi:10.1375/twin.2.4.274

Roorda, D. L., Koomen, H. M. Y., Spilt, J. L., \& Oort, F. J. (2011). The influence of affective teacher-student relationships on students' school engagement and achievement: a meta-analytic approach. Review of Educational Research, 81, 493 - 529. doi:10.3102/0034654311421793

This is a post-peer-review, pre-copyedit version of an article published in Journal of Abnormal Child Psychology. The final authenticated version is available online at: https://doi.org/10.1007/s10802- 
Roorda, D. L., Verschueren, K., Vancraeyveldt, C., Van Craeyevelt, S., \& Colpin, H. (2014). Teacher-child relationships and behavioral adjustment: Transactional links for preschool boys at risk. Journal of School Psychology, 52(5), 495-510.

Rueger, S. Y., Malecki, C. K., Pyun, Y., Aycock, C., \& Coyle, S. (2016). A meta-analytic review of the association between perceived social support and depression in childhood and adolescence. Psychological Bulletin, 142, 1017-1067.

Satorra, A., \& Bentler, P. M. (2001). A scaled difference chi-square test statistic for moment structure analysis. Psychometrika, 66, 507-514.http://dx.doi.org/10.1007/BF02296192

Skinner, E. A., \& Belmont, M. J. (1993). Motivation in the classroom: Reciprocal effects of teacher behavior and student engagement across the school year. Journal of Educational Psychology, 85(4), 571-581. doi:10.1037/0022-0663.85.4.571

Spence, S. H., \& Shortt, A. L. (2007). Research Review: Can we justify the widespread dissemination of universal, school-based interventions for the prevention of depression among children and adolescents? Journal of Child Psychology and Psychiatry, 48(6), 526-542.

Spilt, J. L., \& Hughes, J. N. (2015). African American Children at Risk of Increasingly Conflicted TeacherStudent Relationships in Elementary School. School Psychology Review, 44(3), 306-314.

Spilt J., Koot J., van Lier P. (2013). For Whom Does It Work? Subgroup Differences in the Effects of a SchoolBased Universal Prevention Program. Prevention Science, 14 (5), 479-488.

Sar, A. M., \& Goudswaard, M. (2001). Docenthandleiding Taakspel voor basisonderwijs. Rotterdam: Pedologisch Instituut.

Verschueren, K., \& Koomen, H. M. Y. (2012). Teacher-child relationships from an attachment perspective. Attachment \& Human Development, 14(3), 205-211. doi:10.1080/14616734.2012.672260

Wellborn, J., Connell, J., Skinner, E., \& Pierson, L. (1992). Teacher as Social Context (TASC). Two Measures of Teacher Provision of Involvement, Structure, and Autonomy Support. Rochester: University of Rochester.

Witvliet, M., Van Lier, P. A., Cuijpers, P., \& Koot, H. M. (2009). Change and stability in childhood clique membership, isolation from cliques, and associated child characteristics. Journal of Clinical Child \& Adolescent Psychology, 39(1), 12-24.

Zhang, X., \& Sun, J. (2011). The Reciprocal Relations Between Teachers' Perceptions of Children's Behavior Problems and Teacher-Child Relationships in the First Preschool Year. The Journal of Genetic Psychology, 172(2), 176-198. doi:10.1080/00221325.2010.528077 
Tables

Table 1. Descriptive statistics

\begin{tabular}{|c|c|c|c|c|c|c|c|c|c|c|c|c|c|c|}
\hline & & $M$ & SD & 1 & 2 & 3 & 4 & 5 & 6 & 7 & 8 & 9 & 10 & 11 \\
\hline 1 & Involvement $_{\mathrm{w} 1}$ & 3.10 & 0.42 & - & & & & & & & & & & \\
\hline 2 & Involvement $_{\mathrm{w} 2}$ & 3.26 & 0.46 & $.64^{* *}$ & - & & & & & & & & & \\
\hline 3 & Involvement $_{\mathrm{w} 3}$ & 3.04 & 0.37 & .07 & $.09^{*}$ & - & & & & & & & & \\
\hline 4 & Involvement $_{\mathrm{w} 4}$ & 3.19 & 0.45 & $.13^{* *}$ & $.10^{*}$ & $.66^{* *}$ & - & & & & & & & \\
\hline 5 & T-Depression ${ }_{\mathrm{w} 1}$ & 1.56 & 0.56 & $-.49^{* *}$ & $-.32^{* *}$ & .00 & $-.11^{*}$ & - & & & & & & \\
\hline 6 & T-Depression ${ }_{\mathrm{w} 2}$ & 1.62 & 0.58 & $-.34^{* *}$ & $-.38^{* *}$ & -.01 & $-.14^{* *}$ & $.58^{* *}$ & - & & & & & \\
\hline 7 & T-Depression ${ }_{\mathrm{w} 3}$ & 1.70 & 0.63 & $-.10^{*}$ & -.04 & $-.43^{* *}$ & $-.49^{* *}$ & $.18^{* *}$ & $.21^{* *}$ & - & & & & \\
\hline 9 & P-Depression ${ }_{\mathrm{w} 1}$ & 0.09 & 0.11 & .02 & .07 & .05 & .06 & .08 & .08 & $.16^{* *}$ & $.18^{* *}$ & - & & \\
\hline 10 & P-Depression ${ }_{\mathrm{w} 2}$ & 0.11 & 0.14 & -.07 & .01 & .04 & .03 & $.14^{* *}$ & $.14^{* *}$ & $.16^{* *}$ & $.13^{* *}$ & $.60^{* *}$ & - & \\
\hline 11 & P-Depression ${ }_{\mathrm{w} 3}$ & 0.12 & 0.14 & .04 & .08 & .05 & .05 & .08 & $.16^{* *}$ & $.20^{* *}$ & $.18^{* *}$ & $.61^{* *}$ & $.70^{* *}$ & - \\
\hline 12 & P-Depression ${ }_{\mathrm{w} 4}$ & 0.11 & 0.14 & -.03 & -.03 & -.02 & .00 & $.11^{* *}$ & $.18^{* *}$ & $.23^{* *}$ & $.23^{* *}$ & $.54^{* *}$ & $.64^{* *}$ & $.70^{* *}$ \\
\hline
\end{tabular}

Note: $\mathrm{T}=$ Teacher-rated; $\mathrm{P}=$ Peer-rated; $\mathrm{W}=$ Wave

Table 2. Significant cross-lagged associations between teacher involvement and child depressive symptoms in the final models

\begin{tabular}{|c|c|c|c|}
\hline Cross-lagged Paths & $\mathrm{B}$ & $S E$ & $\beta$ \\
\hline $\begin{array}{l}\text { Teacher-reported Child depressive symptoms } \\
\text { Involvement }_{\mathrm{w} 1} \rightarrow \text { Depression }_{\mathrm{w} 2}\end{array}$ & -0.180 & $0.070 * *$ & -0.130 \\
\hline Involvement $_{\mathrm{w} 3} \rightarrow$ Depression $_{\mathrm{w} 4}$ & -0.180 & $0.070 * *$ & -0.118 \\
\hline Depression $_{\mathrm{w} 4} \rightarrow$ Involvement $_{\mathrm{w} 4}$ & -0.168 & $0.051 * *$ & -0.233 \\
\hline \multicolumn{4}{|l|}{ Peer-reported Child depressive symptoms } \\
\hline Involvement $_{\mathrm{w} 1} \rightarrow$ Depression $_{\mathrm{w} 2}$ & -0.026 & $0.009 * *$ & -0.077 \\
\hline Involvement $_{\mathrm{w} 2} \rightarrow$ Depression $_{\mathrm{w} 3}$ & 0.022 & $0.008 * *$ & 0.076 \\
\hline Involvement $_{\mathrm{w} 3} \rightarrow$ Depression $_{\mathrm{w} 4}$ & -0.026 & $0.009 * *$ & -0.068 \\
\hline Involvement $_{\mathrm{w} 3} \rightarrow$ Depression $_{\mathrm{w} 4}-$ Boys & 0.005 & 0.011 & 0.017 \\
\hline Involvement $_{\mathrm{w} 3} \rightarrow$ Depression $_{\mathrm{w} 4}-$ Girls & -0.048 & $0.015 * *$ & -0.118 \\
\hline
\end{tabular}

Note: $* p<.05, * * p \leq .01 ; \mathrm{W}=$ wave

This is a post-peer-review, pre-copyedit version of an article published in Journal of Abnormal Child Psychology. The final authenticated version is available online at: https://doi.org/10.1007/s10802-018-0441-7. 
Figures

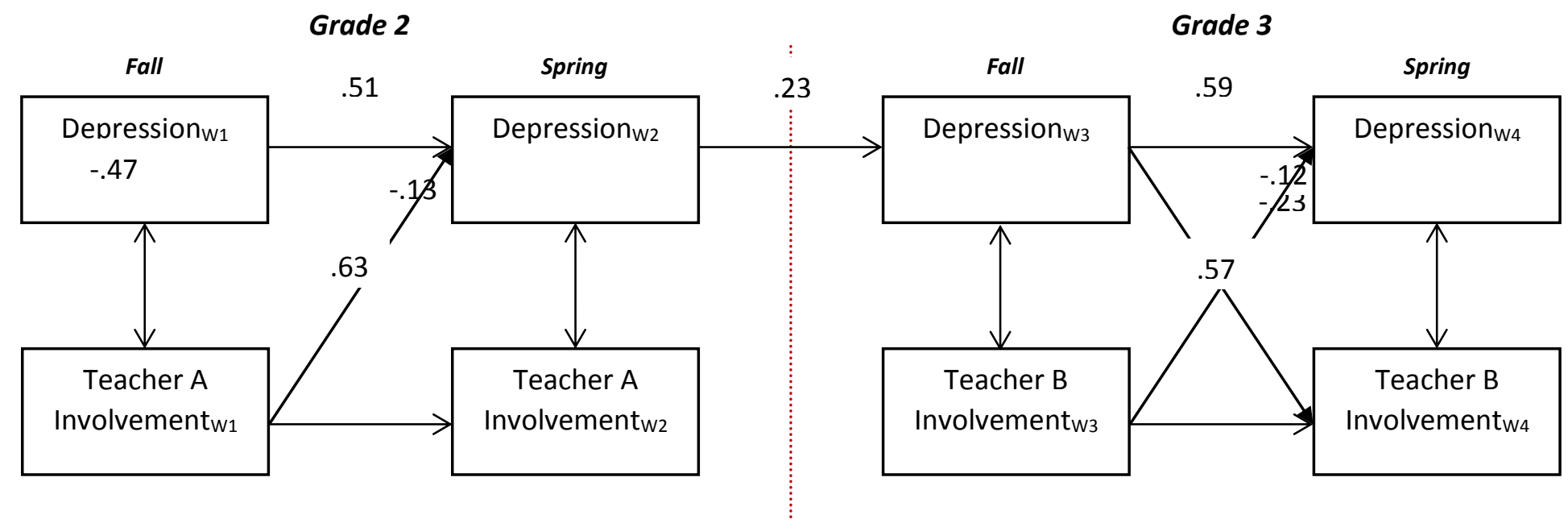

Figure 1. Final model of Teacher Involvement and Teacher-reported Child Depressive Symptoms.

Note: Only significant paths are depicted. Standardized coefficients are reported. Children had different teachers in Grade 2 (Teacher A) and Grade 3 (Teacher B). 


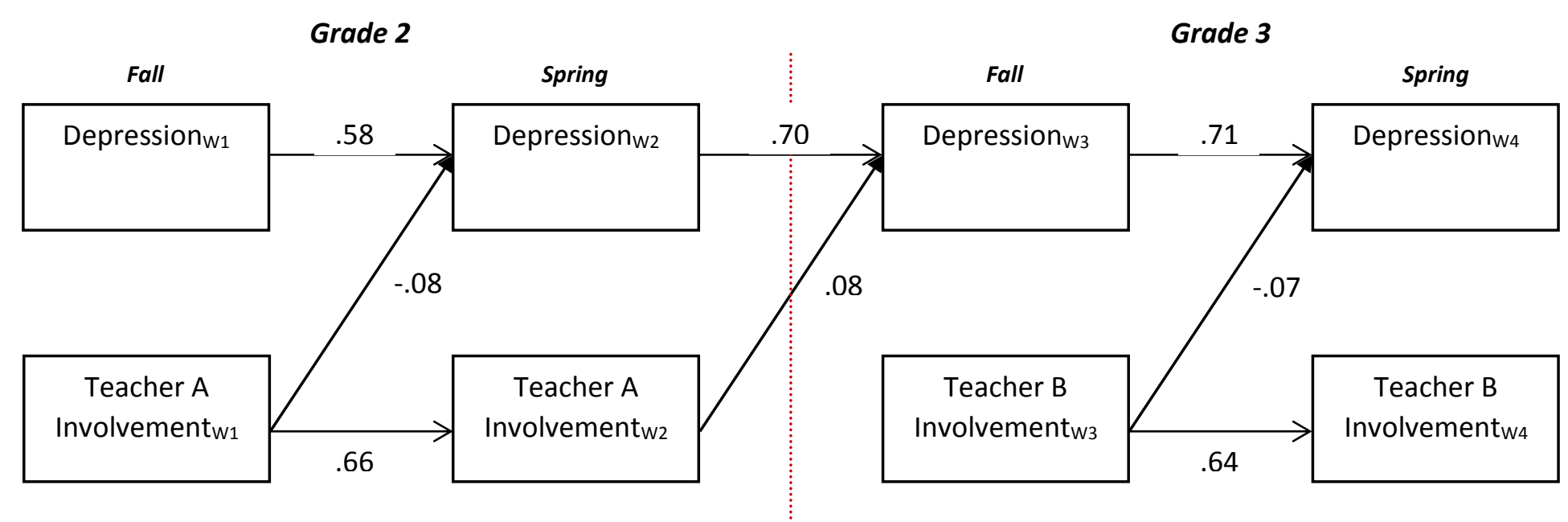

Figure 2. Final model of Teacher Involvement and Peer-reported Child Depressive Symptoms. online at: https://doi.org/10.1007/s10802-018-0441-7. 